\title{
Epilogue: The Next Reel for Entertainment-Education
}

\author{
Paul Falzone and Lauren B. Frank
}

In this collection we endeavored to bring together many of the preeminent theorists, researchers, and practitioners of entertainment-education (EE) to make sense of the field's history and present moment. New technology has radically transformed the field since the early 2000 s, and recent review articles have highlighted challenges and recommendations (Chatterjee, Sangalang, \& Cody, 2017; Sood, Riley, \& Alarcon, 2017; Storey \& Sood, 2013). Thus, we asked each chapter author to answer some of those outstanding questions and to recommend practical advice, lessons learned, and best practices for working in the field going forward.

P. Falzone

Peripheral Vision International, Brooklyn, NY, USA

e-mail: director@pvinternational.org

L. B. Frank $(\bowtie)$

Portland State University, Portland, OR, USA

e-mail: lfrank@pdx.edu

(C) The Author(s) 2021

L. B. Frank, P. Falzone (eds.), Entertainment-Education Behind the

Scenes, https://doi.org/10.1007/978-3-030-63614-2_21 


\section{Lessons Learned and Best Practices}

In compiling the recommendations this volume offers, we have grouped them into categories on media channels and distribution, research, theory, message design, relationship building, and growing the EE field. We highlight ways in which they overlap or suggest contradictory directions. Some of the recommendations reiterate important guidelines that have long grounded our field, and others offer new suggestions that reflect rapidly changing media environments. These recommendations leave us with the question: where does the field go from here? What questions and developments will emerge, and what must be addressed in the next key collection in this field, whether that be 5,10 , or 15 years down the road? Prognostication is a risky proposition, but we would anticipate that the next collection will need to fill in the blanks that our own historical moment was unable to address.

\section{Media Channels and Distribution}

With the advent of new digital technologies, the case studies in this collection detail many innovative new EE formats that rely on digital and social media (e.g. Bouman, 2021; Sabido, 2021). Recent EE interventions use transmedia storytelling in which multiple channels tell consistent stories to reach and engage audiences (e.g. Chatterjee, Pasricha, Mitra, \& Frank, 2021; Ryerson \& Negussie, 2021; Wang \& Singhal, 2021). Not only do we need transmedia campaigns that tell a single story, but also we need multiple different campaigns that all work together to affect social norms over time (Borum Chattoo, 2021). M. Green (2021b), D. Green (2021a), and Murphy (2021) call for more research to understand how much exposure to a campaign is necessary for change in knowledge, attitudes, social norms, and behaviors. As Falzone and Lukomska (2021) highlight, we must plan for distribution from the beginning of developing a new EE initiative. This includes considering which media channels are most appropriate and what schedule makes the most sense. As Bouman (2021) notes, audience expectations in the online realm are not the single new episode each week; viewing patterns have changed, and binge-watching is becoming more common.

What new platforms, channels, and media have emerged as distribution channels, and what unique challenges and opportunities do they present? At the time of this writing, TikTok is emerging as a popular platform, and 
examples like the Vietnam handwashing choreography (\#vudieuruatay \#handwashingmove; see Chirinos-Espin, 2021) have already shown what possibilities this platform may offer to advance EE.

The advances of new digital technologies hold promise for innovative new EE formats. However, they can also leave behind those with less access to media. To reach these less connected audiences, Chirinos-Espin (2021) collaborates on music interventions with songs that resonate with audiences, Jahn (2021) describes her literacy work through live performances, and Falzone and Lukomska (2021) use basic mobile phones, offgrid, and out-of-home venues. What are the ethical implications of the digital divide? Are there ways to combine old and new media channels within the same campaign to reach more of the audience? Perhaps a new initiative by Johns Hopkins University Center for Communication Programs (JHU CCP) to promote malaria testing and treatment in Guyana will help to answer this question. They plan to use a mix of social media and WhatsApp, along with more static media such as DVDs and flash drives.

\section{Research}

Echoing recent reviews of the field (Sood et al., 2017; Storey \& Sood, 2013), many of the chapters end with explicit recommendations for research. There is strong agreement on the importance of using formative research with audience members to develop and pilot messages. Moreover, Chirinos-Espin (2021), D. Green (2021a), and Murphy (2021) call for funding of and planning for outcome evaluation from the beginning. However, there is disagreement on exactly what kind of research should count as evidence for our field. While some scholars call for more robust designs that are better able to demonstrate causal impacts from EE campaigns (D. Green, 202la), others focus on the need to adapt research methodologies to the realities of the field (e.g., Gowland, Colquuhoun, Nyoi, \& Thawng, 2021; Rosenthal \& Folb, 2021; Wang \& Singhal, 2021 ). Both sets of concerns are important, and balancing the two with limited resources is especially difficult. Laboratory studies (e.g. Ophir, Sangalang, \& Cappella, 2021) can provide great insight into the processes that underlie narrative persuasion, but such research does not always translate to how people actually experience EE campaigns (D. Green, 202la; Wang \& Singhal, 2021). As Riley, Rodrigues, and Sood (2021) note, large changes in social norms cannot result from a single program, and indeed, 
most rigorous study finds small effects (D. Green, 2021a). Perhaps iterative pretesting of alternative story features can increase the impact that EE interventions can have (D. Green, 202la).

Studies of EE's impact are still largely dependent on surveys and selfreport. It is possible that as more advanced measurement tools and technologies emerge and evolve, including biometric tools that are not currently operating at scale, we may have a more nuanced understanding of how persuasion operates. Bernard and Francis (2021) and Bouman (2021) highlight opportunities for using hashtags and tools embedded within social media for ongoing measurement of engagement with EE campaigns. Wang and Singhal (2021) mention the use of social network analysis to improve evaluation. There is also the potential to establish broader consensus or consistency across studies. The Participant Index (TPI), developed by Participant Media and the Norman Lear Center, attempted to quantify the relative social impact of films, TV shows, and online video in the United States and indicates a direction that EE might take. Is there the potential to develop generalized scales that measure social impact of EE in a more global context? Paired with a cost-perimpression analysis, such measures might put us on a path to understand the benefits of investing in EE solutions as opposed to other approaches.

\section{Theory}

As Obregon, Wendorf Muhamad, and Lapsansky (2021) note, entertainment-education and the broader field of social and behavior change communication (SBCC) value interventions that are grounded in theory. However, they and others call for more communication theories and question how theory is currently applied. Notably, Cole and Piotrowski (2021) recommend the use of information processing theories that already drive entertaining media for children. Incorporation of critical theory can also improve the field (Chatterjee et al., 2021; Chirinos-Espin, 2021). Many authors reiterate the need for multi-level theories and socioecological models that speak not only to individual processing of EE campaigns but also to institutions and societies (Borum Chattoo, 2021; Obregon et al., 2021; Wang \& Singhal, 2021). From its inception, EE has focused on social change with a goal of impacting not only individuals but also societal norms. However, many of the theories that most directly ground $\mathrm{EE}$ interventions focus on individual message processing. Given the importance of talking about campaigns for how they create change (Frank 
et al., 2012; Southwell \& Yzer, 2009), our theories must better incorporate the viewing environment.

Riley et al. (2021) mark the need for theory to be accessible for practitioners. We currently have a large array of theories available, and we can look to many other fields to become truly transdisciplinary. However, we must always tie theory to practical advice for creating and implementing campaigns. Many practitioners rely on applied "theories of change" rooted in their local contexts that draw upon a few academic concepts without taking advantage of entire theories. Given that many of the theories available to the field were developed in Western contexts and focus on individuals (Dutta, 2008), this adaptation is unsurprising. Development and progression of theory should not live within academic literature alone. Going forward, how can we best adapt and iterate theories with our audiences and stakeholders to create overarching theories that reflect local understandings?

\section{Message Design}

As explained by M. Green (2021b), there are many possible ways to use theory to design effective EE content. Indeed, we will never be able to fully create a formula for crafting messages because novelty is part of what engages audiences. That said, the case studies here provide practical lessons that can guide content creators. Stories should make sense and be believable within the local context (M. Green, 2021b; Obregon et al., 2021). It helps if the educational content is part of the primary storyline, rather than incidental to the script (M. Green, 2021b); however, it's essential to prioritize entertainment over education to ensure what your audience wants to watch (Bouman, 2021). Content that people value can be shared and increase overall exposure to the campaign message (Bernard \& Francis, 2021). Although no clear pattern of emotional flow has emerged as best (Ophir et al., 2021), tapping into emotions can help to avoid being one more message in an environment of information overload (Chirinos-Espin, 2021). Characters who are relatable, particularly the protagonists, are key (Ophir et al., 2021; Ryerson \& Negussie, 2021).

There is tension in how much the prosocial message should push for change. Ryerson and Negussie (2021) recommend that messages be tied to publicly espoused values of the government, but Chatterjee et al. (2021) note the constraints of not being able to fully challenge social norms. Perhaps the answer lies in relying on cultural advisors (Murphy, 2021) and 
having the audience help to actually shape the message (Chirinos-Espin, 2021). Working from research, theory, and principles grounded therein, what new ideas will emerge to help creators design strong content?

\section{Relationship Building}

A recurring theme across chapters is the importance of relationship building. In order to achieve goals, a diverse array of talents is needed. Bouman (2021) highlights the importance of strong relationships between scholars and creative content designers, as do many others (e.g. Borum Chattoo, 2021 ; M. Green, 2021b; Rosenthal \& Folb, 2021). Relationship building and local capacity building with researchers in the field are also essential (Gowland et al., 2021; Riley et al., 2021; Wang \& Singhal, 2021). Notably, these relationships must move beyond the actual creation and implementation of EE interventions. We must also coordinate with the government and private organizations that may provide access to services that EE programming creates demand for (Ryerson \& Negussie, 2021; Sabido, 2021). Falzone and Lukomska (2021) suggest that relationships with media companies should highlight ways in which providing content can be costeffective for distributors and yield mutual benefits. Going forward, how can we ensure that the list of stakeholders is not limited to those with institutional power? How can we best include our audience as active participants in the co-creation of long-term relationships to promote social change?

\section{Growing the Entertainment-Education Field}

As many of the chapters in this collection illustrate, EE is tasked with the challenge of having to compete in a commercial marketplace, but bound by the twin limitations of needing to have a positive impact and being able to demonstrate that impact. This makes it more expensive to produce and more challenging to script than a purely commercial project. Chatterjee et al. (2021) highlight the importance of funding that is sustainable for long-term projects to allow for incremental social change. At the same time, because it is not driven by audience demand or profit margins, but by broader (and often slower-moving) funding mechanisms, EE operates parallel to, but separate from, commercial projects. This is a challenge and an opportunity. How will practitioners expand and evolve the 
opportunities, while also keeping pace with evolutions in audience taste and the marketplace?

What is clear from this collection is that while there are many examples and practitioners of EE, they are quite disparate and disconnected. Many authors call for opportunities to share effective campaign frameworks (e.g. Obregon et al., 2021; Ryerson \& Negussie, 2021; Sabido, 2021). While $\mathrm{EE}$ has standing in the broader field of Social and Behavior Change Communication (SBCC), there is no consistent conference that brings us all together. Since 1989, there have been six Entertainment Education for Social Change conferences, the most recent being within the 2018 International Social and Behavior Change Communication Summit. Both the Communication Initiative Network and Compass provide spaces for sharing SBCC projects and include sections for entertainment-education (Communication Initiative, n.d.; USAID, n.d.). It is only when we work together that the field can evolve as a whole, and more frequent direct contact yields such opportunities. The opportunity to grow our collaboration, share our tools and findings, and co-create more effectively is not yet fully realized. Doing so requires a more consistent community of practice.

\section{Parting Thoughts from This Moment}

At the time of this collection, we are in the midst of a global pandemic and in the throes of what the World Health Organization calls an "infodemic" related to rampant misinformation, conjecture, rumor, and conspiracies. It seems in this crisis that there is a growing awareness of the power and impact of media on a population's knowledge, beliefs, and behavior and a growing understanding that media and communication are what connect, bind, and potentially divide us. Media can entertain us and inform us. We anticipate that at this moment, we are in the dawn of a deeper respect for the power of media; media must be willfully and more conscientiously studied, funded, shaped, and utilized if we hope to create a better future. As entertainment-education scholars and practitioners, we can be a key part of that future. 


\section{REFERENCES}

Bernard, D., \& Francis, S. (2021). When your audience is your channel: Facebook for behavior change. In L. B. Frank \& P. Falzone (Eds.), Entertainmenteducation behind the scenes: Case studies for theory and practice. Palgrave Macmillan.

Borum Chattoo, C. (2021). Entertainment-education as social justice activism in the United States: Narrative strategy in the participatory media era. In L. B. Frank \& P. Falzone (Eds.), Entertainment-education behind the scenes: Case studies for theory and practice. Palgrave Macmillan.

Bouman, M. (2021). A strange kind of marriage: The challenging journey of entertainment-education collaboration. In L. B. Frank \& P. Falzone (Eds.), Entertainment-education behind the scenes: Case studies for theory and practice. Palgrave Macmillan.

Chatterjee, J. S., Sangalang, A., \& Cody, M. J. (2017). Entertainment-education. The International Encyclopedia of Media Effects, 1-12. https://doi. org/10.1002/9781118783764.wbieme0067

Chatterjee, J. S., Pasricha, R., Mitra, R., \& Frank, L. B. (2021). Challenging the forcefield:Craftingentertainment-education transmediacampaigns. InL.B. Frank \& P. Falzone (Eds.), Entertainment-education behind the scenes: Case studies for theory and practice. Palgrave Macmillan.

Chirinos-Espin, C. (2021). Music and culture in entertainment-education. In L. B. Frank \& P. Falzone (Eds.), Entertainment-education behind the scenes: Case studies for theory and practice. Palgrave Macmillan.

Cole, S., \& Piotrowski, J. T. (2021). Youth and entertainment-education. In L. B. Frank \& P. Falzone (Eds.), Entertainment-education behind the scenes: Case studies for theory and practice. Palgrave Macmillan.

Communication Initiative. (n.d.). The communication initiative network: Convening the communication and media development, social and behaviour change community. Retrieved from https://www.comminit.com/global/category/sites/global

Dutta, M. J. (2008). Communicating health: A culture-centered approach. Polity.

Falzone, P., \& Lukomska, G. (2021). Last mile media: A how-to guide. In L. B. Frank \& P. Falzone (Eds.), Entertainment-education behind the scenes: Case studies for theory and practice. Palgrave Macmillan.

Frank, L. B., Chatterjee, J. S., Chaudhuri, S., Lapsansky, C., Bhanot, A., \& Murphy, S. T. (2012). Conversation and compliance: Role of interpersonal discussion and social norms in public communication campaigns. Journal of Health Communication, 17(9), 1050-1067. https://doi.org/10.1080/ 10810730.2012 .665426

Gowland, S., Colquuhoun, A., Nyoi, M. Y. H., \& Thawng, V. S. (2021). Using audience research to understand and refine a radio drama in Myanmar tackling 
social cohesion. In L. B. Frank \& P. Falzone (Eds.), Entertainment-education behind the scenes: Case studies for theory and practice. Palgrave Macmillan.

Green, D. P. (202la). In search of entertainment-education's effects on attitudes and behaviors. In L. B. Frank \& P. Falzone (Eds.), Entertainment-education behind the scenes: Case studies for theory and practice. Palgrave Macmillan.

Green, M. C. (2021b). Transportation into narrative worlds. In L. B. Frank \& P. Falzone (Eds.), Entertainment-education behind the scenes: Case studies for theory and practice. Palgrave Macmillan.

Jahn, M. M. (2021). How to make a living legend: Bibliobandido as literacy movement building. In L. B. Frank \& P. Falzone (Eds.), Entertainmenteducation behind the scenes: Case studies for theory and practice. Palgrave Macmillan.

Murphy, S. T. (2021). When life gives you lemons: What to do when something goes wrong in your carefully planned research and how to avoid disasters in the first place. In L. B. Frank \& P. Falzone (Eds.), Entertainment-education behind the scenes: Case studies for theory and practice. Palgrave Macmillan.

Obregon, R., Wendorf-Muhamad, J., \& Lapsansky, C. (2021). Strengthening integration of communication theory into entertainment-education practice: Reflections from the La Peor Novela case study. In L. B. Frank \& P. Falzone (Eds.), Entertainment-education behind the scenes: Case studies for theory and practice. Palgrave Macmillan.

Ophir, Y., Sangalang, A., \& Cappella, J. N. (2021). The emotional flow hypothesis in entertainment-education narratives: Theory, empirical evidence, and open questions. In L. B. Frank \& P. Falzone (Eds.), Entertainment-education behind the scenes: Case studies for theory and practice. Palgrave Macmillan.

Riley, A. H., Rodrigues, F., \& Sood, S. (2021). Social norms theory and measurement in entertainment-education: Insights from case studies in four countries. In L. B. Frank \& P. Falzone (Eds.), Entertainment-education behind the scenes: Case studies for theory and practice. Palgrave Macmillan.

Rosenthal, E., \& Folb, K. (2021). Entertainment-education, American style: Informing and studying Hollywood's portrayals of social issues. In L. B. Frank \& P. Falzone (Eds.), Entertainment-education behind the scenes: Case studies for theory and practice. Palgrave Macmillan.

Ryerson, W. N., \& Negussie, N. (2021). The impact of social change communication: Lessons learned from decades of media outreach. In L. B. Frank \& P. Falzone (Eds.), Entertainment-education behind the scenes: Case studies for theory and practice. Palgrave Macmillan.

Sabido, M. (2021). Miguel Sabido's entertainment-education. In L. B. Frank \& P. Falzone (Eds.), Entertainment-education behind the scenes: Case studies for theory and practice. Palgrave Macmillan. 
Sood, S., Riley, A. H., \& Alarcon, K. C. (2017). Entertainment-education and health and risk messaging. In R. Parrott (Ed.), Oxford research encyclopedia of communication. NY: Oxford University Press. https://doi.org/10.1093/ acrefore/9780190228613.013.245

Southwell, B. G., \& Yzer, M. C. (2009). When (and why) interpersonal talk matters for campaigns. Communication Theory, 19(1), 1-8.

Storey, D., \& Sood, S. (2013). Increasing equity, affirming the power of narrative and expanding dialogue: The evolution of entertainment-education over two decades. Critical Arts, 27(1), 9-35. https://doi.org/10.1080/0256004 6.2013 .767015

USAID. (n.d.). The compass for social and behavior change. Retrieved from https:// www.thecompassforsbc.org/

Wang, H., \& Singhal, A. (2021). Mind the gap! Confronting the challenges of translational communication research in entertainment-education. In L. B. Frank \& P. Falzone (Eds.), Entertainment-education behind the scenes: Case studies for theory and practice. Palgrave Macmillan.

Open Access This chapter is licensed under the terms of the Creative Commons Attribution-NonCommercial-NoDerivatives 4.0 International License (http:// creativecommons.org/licenses/by-nc-nd/4.0/), which permits any noncommercial use, sharing, distribution and reproduction in any medium or format, as long as you give appropriate credit to the original author(s) and the source, provide a link to the Creative Commons licence and indicate if you modified the licensed material. You do not have permission under this licence to share adapted material derived from this chapter or parts of it.

The images or other third party material in this chapter are included in the chapter's Creative Commons licence, unless indicated otherwise in a credit line to the material. If material is not included in the chapter's Creative Commons licence and your intended use is not permitted by statutory regulation or exceeds the permitted use, you will need to obtain permission directly from the copyright holder. 